\title{
ANALISIS PERBANDINGAN PENDAPATAN PETANI PALA BASAH DAN KERING DI DESA PANITI HALMAHERA TENGAH
}

\author{
$\mathrm{H}$ a $\mathbf{m ~ k}$ a \\ Staf Pengajar FAPERTA UMMU-Ternate,e-mail: hamka_agb@yahoo.co.id
}

\begin{abstract}
ABSTRAK
Penelitian ini bertujuan Menganalisis besar perbandingan pendapatan antara petani pala basah dan pendapatan petani pala kering. Lokasi penelitian di Desa Paniti, Kecamatan Patani, Kabupaten Halmahera Tengah, pada bulan September-Okbtober 2014. Sampel sebanyak 54 responden dipilih dengan metode sampling jenuh . Analisis data digunakan metode analisis uji $t$ dengan software SPSS 16. Hasil penelitian menujukkan Hasil uji $t$, menunjukkan $t$ hitung sebesar (9.339) sedangkan $t$ tabel $(0,305)$. Dengan demikian berdasarkan hipotesis $t$ hitung $>t$ tabel, yang berarti hipotesis (H0) di terima dan $\mathrm{H1}$ di tolak. Hal ini menunjukan bahwa terdapat perbedaan yang signifikan antara pendapatan petani pala basah terhadap pendapatan petani pala kering.
\end{abstract}

Kata Kunci: Pendapatan, Pala basah, Pala kering

\section{PENDAHULUAN}

1.1. Latar Belakang

Pala Banda (Myristica fragrans Houtt) merupakan salah satu komoditas ekspor potensial andalan pemerintah daerah Maluku, sebagai sumber pertumbuhan ekonomi dan pendapatan daerah tersebut. Pala merupakan tanaman rempah asli kepulauan Maluku (Purseglove et al., 1995), yang telah diperdagangkan dan dibudidayakan secara turun temurun dalam bentuk perkebunan rakyat di sebagian besar kepulauan Maluku.

Pertanian pala baik di masyarakat maupun perusahaan perkebunan, merupakan hasil perbanyakan asal biji (generatif) sehingga masalah sex ratio tidak dapat diatur dari awal pertanaman dan bibit yang digunakan adalah asalan, dengan produktivitas rendah yaitu kurang dari 1500-3000 butir/pohon/tahun (Hadad, 1992). Pemakaian bibit unggul pala klonal (vegetatif) diperlukan pada program pengembangan pala ke depan sehingga masalah sex ratio dapat teratasi dan produksi serta mutu dapat lebih meningkat. Berdasarkan kondisi pala saat ini, Pemerintah Daerah seharusnya segera melakukan perbaikan dengan mengacu teknologi budidaya yang telah tersedia. Teknologi yang tersedia dari hasil penelitian, antara lain teknologi perbanyakan bibit pala unggul klonal (vegetatif), pengolahan biji pala dan fuli menjadi minyak atsiri, teknologi pengolahan minyak atsiri menjadi diversifikasi produk ikutan dan teknologi pengolahan daging buah pala menjadi berbagai macam makanan ringan belum diperoleh di tingkat petani.

Pala adalah salah satu tanaman perkebunan rakyat yang menjadi sumber pendapatan bagi sebagian masyarakat di Desa Peniti. Kecamatan Patani merupakan penghasil pala terbesar di Kabupaten Halmahera Tengah. Buah pala terdiri atas daging buah (pericarp) dan biji yang terdiri atas fuli, tempurung dan daging biji. Fuli adalah serat tipis (areolus) bewarna merah atau kuning muda, berbentuk selaput berlubang-lubang seperti jala yang terdapat antara daging dan biji pala (Hadad, dkk, 2006).

Desa Peniti merupakan salah satu sentra produksi buah pala di Kecamatan Patani 
Kabupaten Halmahera Tengah. Banyaknya tanaman pala yang tumbuh di Kecamatan Patani tersebar di beberapa Desa, diantaranya adalah Desa Peniti. Pada desa ini terdapat potensi yang cukup baik dalam hal tanaman pala. Tabel 1 akan menyajikan Luas Areal dan Produksi Pala di Desa Peniti pada tahun 2011 sampai dengan 2013.

Tabel 1. Luas Areal dan Produksi Pala di Desa peniti Tahun 2011-2013

\begin{tabular}{ccc}
\hline Tahun & $\begin{array}{c}\text { Luas Areal/Lahan yang } \\
\text { Ditempati (Ha) }\end{array}$ & $\begin{array}{c}\text { Produksi } \\
\text { (Ton) }\end{array}$ \\
\hline 2011 & 73.21 & 2.45 \\
2012 & 73.21 & 2.49 \\
2013 & 73.21 & 3.12
\end{tabular}

Sumber : Dishut Kab. Halteng, 2014

Potensi yang dimiliki, usahatani ini berpeluang untuk dibenahi baik secara teknis maupun dalam hal penataan kelembagaannya. Dalam hal ini lembaga pemasaran diharapkan mampu mengatasi masalah-masalah pemasaran yang terjadi dengan melakukan fungsi-fungsi pemasaran yang baik. Adanya langkah tersebut diharapkan akan menghasilkan sejumlah tambahan pendapatan yang mampu meningkatkan kesejahteraan petani dan masyarakat.

Petani pala di Desa Peniti ini menjual hasil panennya dalam bentuk basah dan kering. Dalam bentuk basah disini maksudnya setelah panen petani langsung dijual kepada pedagang pengumpul desa (PPD) tanpa dilakukan pengeringan / penjemuran. Sedangkan penjualan dalam bentuk kering disini maksudnya petani setelah melakukan pengupasan kulit pala, biji pala tersebut dipisahkan dengan fulinya. Biji pala dan fuli tersebut dijemur menggunakan sinar matahari ( \pm 2 hari tergantung cuaca) atau dengan pengasapan menggunakan api kecil (tumpukan sabut kelapa) selama empat jam atau satu hari tergantung banyak hasil produksi pala. Dalam penjualan pala baik yang basah maupun yang kering, petani di Desa Peniti ini tidak memanfaatkan daging buah pala.

Pemasaran pala yang dilakukan oleh petani di desa peniti pada umumnya menjual palanya dalam bentuk basah $62,5 \%$ kepada pedagang pengumpul desa seharga Rp. 1700 / biji.
Sedangkan petani yang menjual pala dalam bentuk kering 37,5 \% dengan harga jual biji kering Rp. $60.000 / \mathrm{kg}$ dan harga jual fulinya Rp. 90.000 / kg. Penjualan fuli ini lebih mahal daripada penjualan biji palanya.

Dalam hal ini terdapat perbedaan harga yang besar antara penjualan biji pala dalam bentuk basah dengan penjualan biji pala setelah dilakukan pengeringan. Apabila menjual dalam bentuk basah, maka fuli pala tidak terhitung. Secara tidak langsung petani pala akan rugi menjual pala dalam bentuk basah. Dengan demikian berapa besar signifikansi perbedaan pendapatan petani pala yang menjual dalam bentuk basah dan yang menjual dalam bentuk kering menjadi penting untuk diketahui.

\subsection{Tujuan Penelitian}

Adapun tujuan yang ingin dicapai dari penelitian ini adalah Menganalisis besar perbandingan pendapatan antara petani pala basah dan pendapatan petani pala kering.

\section{METODE PENELITIAN}

\subsection{Lokasi dan Waktu Penelitian}

Penelitian ini akan dilaksanakan di Desa Peniti Kecamatan Patani. Pemilihan lokasi ini dilakukan secara sengaja (purposive) dengan pertimbangan bahwa Desa Peniti merupakan salah satu sentral produksi pala di Kecamatan Patani Kabupaten Halmahera Tengah. Penelitian ini dilakukan pada bulan April - Juni 2014.

\subsection{Metode Penentuan Sampel}

Jumlah responden yang menjual pala dalam bentuk basah adalah 31 orang. Sedangkan yang menjual pala dalam bentuk kering sebanyak 23 orang sehingga total responden berjumlah 54 orang, penarikan sampel menggunakan metode sampling jenuh dimana teknik penentuan sampel bila semua anggota populasi digunkaan sebagai sampel (Sugiono, 2011). Pengambilan sempel dilakukan atas dasar pendekatan langsung ke responden dengan panduan dari peneliti. Dalam hal ini, penulis akan mewawancarai responden sehingga dapat diperoleh informasi lebih dalam. 


\subsection{Metode Pengumpulan Data}

Penelitian menggunakan dua macam metode pengambilan data yaitu data primer dan data sekunder, dengan penjelasan sebagai berikut :

a. Data Primer

Data primer adalah yang diperoleh lewat wawancara dengan responden, dengan bantuan kuesioner.

b. Data Sekunder

Data sekunder adalah data yang diperoleh atau dikumpulkan oleh pihak lain. Dapat bersumber dari pustaka dan lembaga yang terkait dengan penelitian ini. Data dalam penelitian ini bersumber dari Dinas Pertanian dan Kehutanan Kabupaten Halmahera Tengah, dan instansi lain yang berkaitan dengan penelitian.

2.4. Metode Analisis Data

2.4.1. Pendapatan

Pendapatan petani pala basah dan petani pala kering dianalisis dengan rumus Hadisapoetra (1973) :

$P d \mathrm{U}=\mathrm{H} \times \mathrm{Y}$

Keterangan :

PdU : Pendapatan Petani Pala Basah dan Petani Pala Kering (Rp/Th).

H : Harga Produksi Usahatani Pala Basah dan Pala Kering Rp/Kg.

Y : Hasil Produksi Petani Pala asah/Petani Pala Kering

Untuk mendapatkan sampel yang dapat mengambarkan dan mencandrakan populasi, maka dalam penentuan sampel penelitian ini digunakan rumus FormulaSlovin (dalam Umar, 2004:108) sebagai berikut :

$$
n=\frac{N}{1+N e^{2}}
$$

\section{Diman :}

$$
\begin{aligned}
\mathbf{n}= & \text { ukuran sampel } \\
\mathrm{N}= & \text { ukuran populasi } \\
\mathrm{e}= & \text { persen kelonggaran ketidaktelitian } \\
& \text { kerena kesalahan pengambilan } \\
& \text { sampel yang masih dapat ditolerir. }
\end{aligned}
$$

Dari jumlah populasi tersebut dengan tingkat kelonggaran ketidaktelitian sebesar $10 \%$.

\subsubsection{Uji T}

Untuk mengetahui apakah ada perbedean pendapatan petani yang menjual pala basah dan pala kering, maka dilakukan uji t. Rumus uji t yang digunakan adalah sebagai berikut :

$t_{\text {hit }}=\frac{\bar{x}_{1}-\bar{x}_{2}}{\sqrt{\left(n_{1}-1+n_{2}\right) S_{1}^{2}+\left(n_{2}-1\right) S_{2}^{2}\left(n_{1}-n_{2}\right)}}$

Kriteria dari uji $t$ untuk mengetahui perbedaan pendapatan antara petani yang menjual pala dalam bentuk basah dan petani pala yang menjual dalam bentuk kering (Usman dan Purnomo, 2003) adalah sebagai berikut :

a. Jika $t$ hitung $>t$ tabel, maka $\mathrm{HO}$ diterima, berarti ada perbedaansignifikan antara pendapatan pada petani yang menjual pala kering dengan pendapatan petani yang menjual pala basah.

b. Jika $\mathbf{t}$ hitung $<\mathbf{t}$ tabel, maka H1 di tolak, berarti tidak ada perbedaan signifikan antara pendapatan petani yang menjual pala basah dengan petani yang menjual pala kering.

\section{HASIL DAN PEMBAHASAN}

Kepemilikan pohon pala yang dimiliki oleh petani pala di Desa Peniti tidak sama antara satu petani dengan petani lain. Sebaran pohon pala di Desa Peniti tidak hanya pada areal perkebunan masyarakat tetapi juga di pekarangan-pekarangan rumah masyarakat desa Paniti. Hal ini dilakukan dengan tujuan agar kepemilikan pohon pala semakin banyak dan dapat meningkatkan pendapatan petani. Adapun jumlah kepemilikan pohon pala di Desa Paniti dapat di lihat pada tabel 3 dibawah ini.

Tabel 1 menunjukkan bahwa (31.48\%) adalah petani yang memiliki pohon pala dari di atas 40 pohon. Sedangkan petani yang memiliki jumlah pohon pala $25-29$ sebesar $(57.41 \%)$ dan (11.11\%) adalah petani yang memiliki jumlah pohon pala di bawah 25 pohon.

Produksi yang diperjual belikan oleh petani adalah pala dalam bentuk biji basah dan 
dan biji kering. Nilai produksi merupakan nilai dari pala yang dihasilkan petani, diperoleh dengan jalan mengalikan jumlah produksi dengan harga jual. Besarnya nilai produksi antar petani akan berbeda, hal ini dipengaruhi oleh banyaknya pohon pala yang dimiliki dan juga mutu pala yang akan dijual.

Pendapatan petani pala merupakan penerimaan petani selama dalam kegiatan usahatani pala. Pada saat penelitian, harga ratarata penjualan dalam bentuk pala basah adalah Rp 1700 per biji, Rp 60.000 per kilogram untuk penjualan dalam bentuk biji kering dan penjualan fuli adalah Rp 90.000 per kilogram. Tabel 2 akan menggambarkan nilai produksi petani pala di lokasi penelitian.

Tabel 1. Kepemilikan Pohon Pala Petani Responden

\begin{tabular}{clcc}
\hline No & Jumlah Pohon & Jumlah Petani Responden & Presentase (\%) \\
\hline 1 & $>40$ & 17 & 31.48 \\
2 & $25-39$ & 31 & 57.41 \\
3 & $<25$ & 6 & 11.11 \\
\hline & Total & 54 & 100.00 \\
\hline
\end{tabular}

Sumber : Data Primer setelah di olah, 2014

Tabel 2. Nilai Produksi Rata-rata per Pohon Pala di Desa Peniti Kecamatan Patani Kabupaten Halmahera Tengah 2014

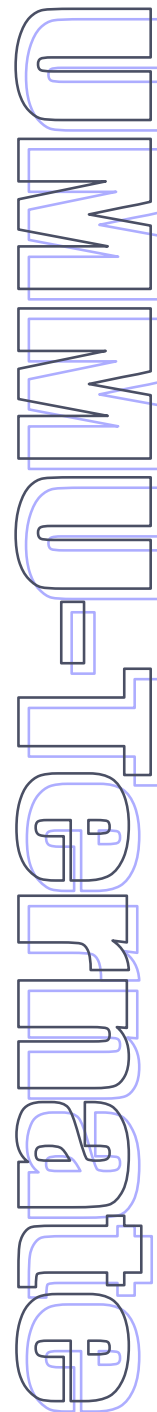

\begin{tabular}{lccc}
\hline \multicolumn{1}{c}{ Usahatani pala } & Jumlah produksi (bij//Kg) & $\begin{array}{c}\text { Harga } \\
(\mathbf{b i j / / k g})\end{array}$ & $\begin{array}{c}\text { Penerimaan } \\
(\mathbf{R p})\end{array}$ \\
\hline $\begin{array}{l}\text { Petani pala basah } \\
\text { Biji basah }\end{array}$ & $90 \mathrm{biji}$ & $\mathrm{Rp} 1700$ & $\mathrm{Rp} \mathrm{153.000,-}$ \\
$\begin{array}{l}\text { Petani pala kering } \\
-\quad \text { Biji kering }\end{array}$ & $3 \mathrm{Kg}$ & $\mathrm{Rp} 60.000$ & $\mathrm{Rp} \mathrm{180.000,-}$ \\
$-\quad$ Fuli & $0,7 \mathrm{Kg}$ & $\mathrm{Rp} 90.000$ & $\mathrm{Rp} \mathrm{63.000,-}$ \\
\hline
\end{tabular}

Sumber : data Primer setelah di olah, 2014

Berdasarkan tabel di atas diketahui bahwa rata-rata jumlah produksi per pohon adalah sebanyak 90 biji untuk pala biji basah, sedangkan untuk pala biji kering $3 \mathrm{~kg}$ dan fuli $0,7 \mathrm{~kg}$.

Petani pala sebagian besar (62,5 persen) menjual hasil produksi pala dalam bentuk biji basah dan (37,5 persen) menjual dalam bentuk biji kering. Petani yang melakukan penjualan dalam bentuk ini dengan alasan tidak memerlukan banyak waktu untuk mendapatkan uang. Sedangkan petani yang melakukan penjualan dalam bentuk biji kering, karena harganya cukup berbeda jauh dengan harga biji basah, mereka harus menunggu beberapa hari untuk mendapatkan biji pala yang benar-benar kering. Adapun penjualan pala yang dijual oleh petani dapat dilihat pada Tabel 3

\subsection{Pendapatan Usahatani Pala}

Rata-rata pendapatan petani pala basah dan petani pala kering dapat disajikan pada Tabel 4. Tabel 4 menunjukkan bahwa rata-rata pendapatan petani pala basah sebesar $R p$ $54,085,512$ per panen. Sedangkan rata-rata pendapatan petani pala kering sebesar $R p$ $109,710,012$ per panen. Perbedaan antara pendapatan tingkat petani pala kering lebih besar dari pada tingkat pendapatan petani pala basah.

\subsection{Analisis Uji $t$}

Analisis perbandingan pendapatan usahatani pala basah dan usahatani pala kering dilakukan dengan analisis uji t. tabel 7 akan menyajikan hasil rata-rata pendapatan petani pala basah dan petani pala kering. 
Tabel 3. Petani Pala Desa Peniti Kecamatan Patani Dalam Menjual Pala

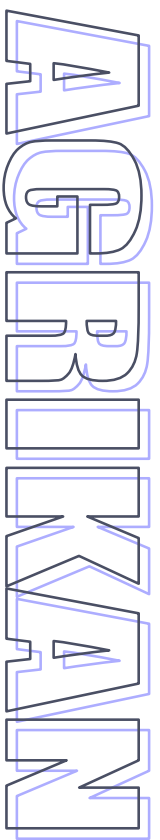

\begin{tabular}{|c|c|c|c|c|}
\hline No & $\begin{array}{l}\text { Bentuk } \\
\text { Penjualan }\end{array}$ & $\begin{array}{l}\text { Jumlah } \\
\text { Petani } \\
\text { (orang) }\end{array}$ & $\begin{array}{c}\text { Persentase } \\
(\%)\end{array}$ & Alasan Pemilihan Bentuk Penjualan \\
\hline 1 & \multirow{2}{*}{$\begin{array}{l}\text { Biji Basah } \\
\text { Biji kering dan } \\
\text { fuli }\end{array}$} & 31 & 57.41 & - lebih cepat mendapatkan uang \\
\hline 2 & & 23 & 42.59 & -. Harga yang menguntungkan \\
\hline & Total & 54 & 100.00 & \\
\hline
\end{tabular}

Sumber : Data Primer setelah di olah, 2014

Tabel 4. Rata-rata Pendapatan Petani Pala Basah dan Petani Pala Kering Tahun 2014

\begin{tabular}{lllll}
\hline \multirow{2}{*}{ Uraian } & \multicolumn{3}{c}{ Pendapatan Rata-Rata Petani Pala } \\
\cline { 2 - 5 } & \multicolumn{3}{c}{ Pala Basah } & \multicolumn{2}{c}{ Pala Kering } \\
\hline Pendapatan (Rp) & $\mathrm{Rp}$ & $54,085,512$ & $\mathrm{Rp}$ & $109,710,012$ \\
\hline
\end{tabular}

Sumber : Data Primer setelah di olah, 2014

Tabel 5. Uji t Pendapatan Petani Biji Pala Basah dengan Pendapatan Petani Biji Pala Kering.

\begin{tabular}{cccc}
\hline \multirow{2}{*}{ Uraian } & \multicolumn{2}{c}{ Uji t } & \multirow{2}{*}{ Perbandingan } \\
\cline { 2 - 3 } & $\mathbf{t}_{\text {hit }}$ & $\mathbf{t}_{\text {tabel }(\alpha=0.05)}$ & \\
\hline Pendapatan (Rp.) & 9.339 & 0.305 & $52 \%$ \\
\hline
\end{tabular}

Sumber : Data Primer setelah di olah, 2014

Berdasarkan Tabel 5, perbandingan pendapatan antara pendapatan petani pala basah dan pendapatan petani pala kering sebesar $52 \%$, diterima pendapatan petani pala kering dua kali lipat, pendapatan petani pala basah dengan perbandingan 1:2.

Hasil uji $t$, menunjukkan $t$ hitung sebesar (9.339) sedangkan $t$ tabel $(0,305)$. Dengan demikian berdasarkan hipotesis $t$ hitung $>t$ tabel, yang berarti hipotesis (H0) di terima dan $\mathrm{H} 1$ di tolak. Hal ini menunjukan bahwa terdapat perbedaan yang signifikan antara pendapatan petani pala basah terhadap pendapatan petani pala kering.

\section{KESIMPULAN}

4.1. Kesimpulan

Berdasarkan hasil penelitian ini, tentang analisis perbandingan pendapatan petani pala basah dan petani pala kering di Desa Peniti Kecamatan Patani Utara, dapat diambil kesimpulan bahwa terdapat perbedaan yang signifikan antara pendapatan petani pala basah dan pendapatan petani pala kering.

\subsection{Saran}

1. Petani yang melakukan penjualan pala basah beralih ke penjualan pala kering karena pendapatan yang akan diterima lebih lebih besar daripada pendapatan apabila menjual dalam bentuk kering, apalagi tidak mengeluarkan biaya untuk pengeringan pala dan waktu yang dibutuhkan dalam proses pengeringan juga tidak begitu lama.

2. Perlunya dukungan dari pemerintah dalam hal penyuluhan mengenai informasi pasar hasil produksi pala

\section{DAFTAR PUSTAKA}

BPS Maluku. 2006. Maluku dalam angka. Maluku in figures 2005/2006 Penerbit BPS Maluku. Ambon. HIm 253-258.

Departemen Pertanian, 2005. Prospek dan Arah Pengembangan Agribisnis Cengkeh. Badan Penelitian dan Pengembangan Pertanian . Departemen Pertanian. 
Direktorat Jendral Bina Produksi Perkebunan, Departemen Pertanian. Statistik Perkebunan Indonesia (Pala : 1986-2001). (Jakarta : 2001).

Hadad, E.A. 1992.Pala. Edisi Khusus LITTRO. Balai Penelitian Tanaman Rempah dan Obat. 8(2):26-37. Hadad, dkk, 2006. Budidaya Pala. Circular No. 5. Badan Penelitian dan Pengembangan Pertanian. Bogor.

Hadad dan Cecep Firman. 2003. Budidaya Pala. Circular No. 5. Badan Penelitian dan Pengembangan Pertanian. Bogor.

Hadisapoetra, S. 1973. biaya dan pendapatan di dalam usaha tani. Departemen Ekonomi Pertanian, Universitas Gajah Mada. Yogyakarta

Hana Bohusova dan Danuse Nerudova. 2009. US GAAP and IFRS Convergence In The Area Of Revenue Recognition. Jurnal Economics dan Management.

Larasati, dkk. 2008. Pengembangan Usahatani Pala dan Usaha Peningkatan Nilai Tambah Produk melalui Pemasaran dengan Pembentukan Kelompok Usaha. Laporan Akhir Program Kreativitas Mahasiswa. Institut Pertanian Bogor. Bogor

Kotler, Philip. 2001. Manajemen Pemasaran di Indonesia : Analisis, Perencanaan, Implementasi dan Pengendalian. Salemba Empat. Jakarta.

Kartasapoetra, G, 1992. Marketing produk pertanian dan industri. Penerbit Renika Cipta. Jakarta

Marzuki, I. 2007. Karakteristik produksi, proksimat atsiri pala Banda. Makalah Pada Seminar Nasional Akselerasi Inovasi Teknologi Pertanian Spesifik Lokasi Mendukung Ketahanan Pangan di Wilayah Kepulauan. BPTP Maluku 29-30 Oktober 2007.

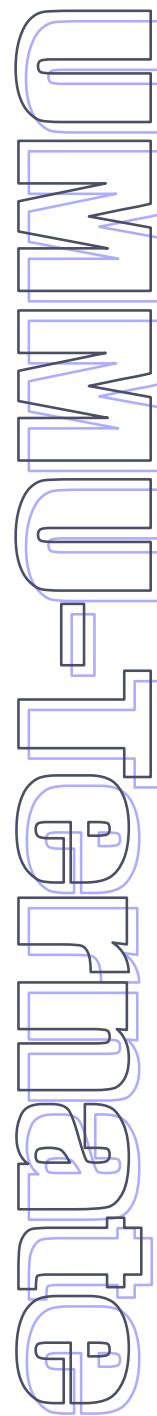

Masdirwan, Herry. 2006. Analisis Efisiensi Saluran Pemasaran Manisan Buah Pala di Desa Dramaga, Kabupaten Bogor. Skripsi. Jurusan Ilmu-ilmu Sosial Ekonomi Pertanian. Fakultas Pertanian. IPB. Bogor.

Naiborhu, 2004. Analisis Kelayakan Finansial da Pemasaran Minyak Pala Studi Kasus PT. Pavettia Atsiri Indonesia Di Bogor. Skripsi. Jurusan Ilmu-ilmu Sosial Ekonomi Pertanian. Fakultas Pertanian. IPB. Bogor

Purseglove, J.W., Brown E.G., Green S.L., and Robbins S.R.J. 1995. Spices. New York: Longmans. pp175-228.

Reny H, 2011. Perbandingan Pendapatan dan Keuntungan petani pala. Skripsi

Rismunandar. 1992. Budidaya dan Tataniaga Pala. PT. Penebar Swadaya. Jakarta.

Sunanto, H. 1993. Budidaya Pala Komoditas Ekspor. Penerbit Kanisius. Yogyakarta.

Syukur, Cheppy. 2002. Budidaya Tanaman Obat Komersial. PT. Penebar Swadaya. Jakarta.

Stanton, William J. 2001. Prinsip Pemasaran. Erlangga. Jakarta.

Swastha, Basu dan Irawan. 2005, Manajemen Pemasaran Modern, Liberty, Yogyakarta.

Sofyan Syafri Harahap. 2008. Teori Akuntansi. Jakarta: PT Raja Grafindo Persada.

Suwardjono. 2010. Teori Akuntansi, Perekayasaan Pelaporan Keuangan (Edisi Ketiga). Yogyakarta: BPFE.

Teken, I. B., 1965. Penelitian di Bidang Ilmu Ekonomi Pertanian dan Beberapa Metoda Pengambilan Contoh. Fakultas Pertanian. Institut Pertanian Bogor.

Usman, Husaini dan Purnomo Setiady. 2003. Statisika Penelitian. PT Bumi Aksara. Jakarta.

Umar Husen, 2004:108, Metode Penelitian Untuk Skripsi Dan Tesis Bisnis, Cet ke 6, Jakarta : PT RajaGrafindo Persada 